\title{
Alleraciones gingivales no relacionadas con placa
}

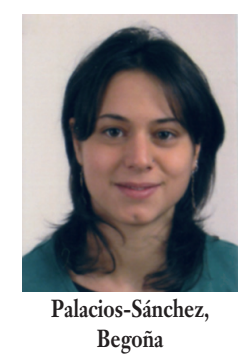

Non-plaque related gingival conditions

\section{Palacios-Sánchez, Begoña* Cerero-Lapiedra, Rocio** Cатро-Тгарего, Julián** Esparza-Gōmez, Germán C. *}

* Licenciada en Odontología por la
UCM
** Profesora Contratada Doctora Departamento de Medicina y Cirugía Bucofacial. Facultad de Odontología de la UCM.

*** Profesor Contratado Doctor. Departamento de Medicina y Cirugía Bucofacial. Facultad de Odontología de la UCM.

**** Profesor Titular. Departamento de Medicina y Cirugía Bucofacial. Facultad de Odontología de la UCM.
Resumen: El depósito de placa bacteriana constituye el principal factor etiológico de las alteraciones gingivales; sin embargo se debe tener en cuenta que las lesiones gingivales pueden ser la manifestación de múltiples procesos en los cuales la placa no constituye el factor principal. Debido a la importancia que pueden tener algunos de estos procesos y a que las lesiones gingivales pueden ser un signo temprano que pueden ayudar a establecer un diagnóstico precoz, se ha propuesto hacer una revisión de los mismos destacando las alteraciones gingivales que aparecen relacionadas con enfermedades mucocutáneas, con niveles hormonales, con los tratamientos farmacológicos, con las infecciones víricas, con las discrasias sanguíneas y, por último, las alteraciones gingivales de origen genético o fibromatosis gingival hereditaria.

Palabras clave: Encía, Gingivitis descamativa crónica, Hiperplasia gingival.

Abstract: Dental plaque remains the main aetiological factor of gingival diseases; nevertheless, a number of gingival lesions could be the expression of other, non-plaque related entities. The aim of this paper is to perform a review and underscore the importance of some of these diseases, since they can be an early and useful sign in order to establish an accurate diagnosis. The main entities are: gingival lesions related to mucocutaneous diseases, gingival lesions related to hormonal levels, gingival alterations produced by pharmacological treatments, gingival lesions produced by viral infections, gingival alterations related to haematological disorders and, finally, gingival alterations of genetic origin such as gingival fibromatosis.

Key words: Gingiva, Chronic desquamative gingivitis, Gingival hyperplasia.

BIBLID [1138-123X (2006)11:1; enero-febrero 1-140]

Palacios-Sánchez B, Cerero-Lapiedra R, Campo-Trapero J, Esparza Cómez GC. Alteraciones gingivales no relacionadas con placa. RCOE 2006;11(1):43-55.
Begoña Palacios Sánchez.

C/ Los Pajaritos 27, $3^{\circ} \mathrm{A}$.

28007 Madrid

E-mail: begopalsan@gmail.com 


\section{Introducción}

A pesar de que la placa bacteriana constituye el principal factor etiológico en la mayoría de las alteraciones gingivales, algunas de ellas pueden estar causadas por procesos diferentes que el profesional debe conocer y tener en cuenta a la hora de establecer el diagnóstico correcto y poder instaurar el tratamiento adecuado. Además también se debe conocer que la encía es, en ocasiones, el primer lugar donde asientan lesiones que pueden ser el signo clínico de procesos sistémicos subyacentes algunos de los cuales presentan una elevada morbilidad.

El objetivo de este artículo es realizar una revisión de las principales patologías en las cuales pueden aparecer lesiones en la encía y para que su estudio resulte más sencillo se han estructurado en seis grupos: aquellas alteraciones gingivales que aparecen relacionadas con enfermedades mucocutáneas y cuya principal manifestación es la gingivitis descamativa crónica; las alteraciones gingivales relacionadas con niveles hormonales entre las que destacan la gingivitis del embarazo y el granuloma gravídico; las alteraciones gingivales relacionadas con los tratamientos farmacológicos como las reacciones liquenoides que pueden manifestarse en la encía y las hiperplasias gingivales; las alteraciones gingivales relacionadas con infecciones víricas (principalmente VIH y la familia de los herpesvirus humanos (VHH)); las alteraciones gingivales relacionadas con discrasias sanguíneas, siendo la leucemia la principal alteración sanguínea con repercusión gingival y, por último, las

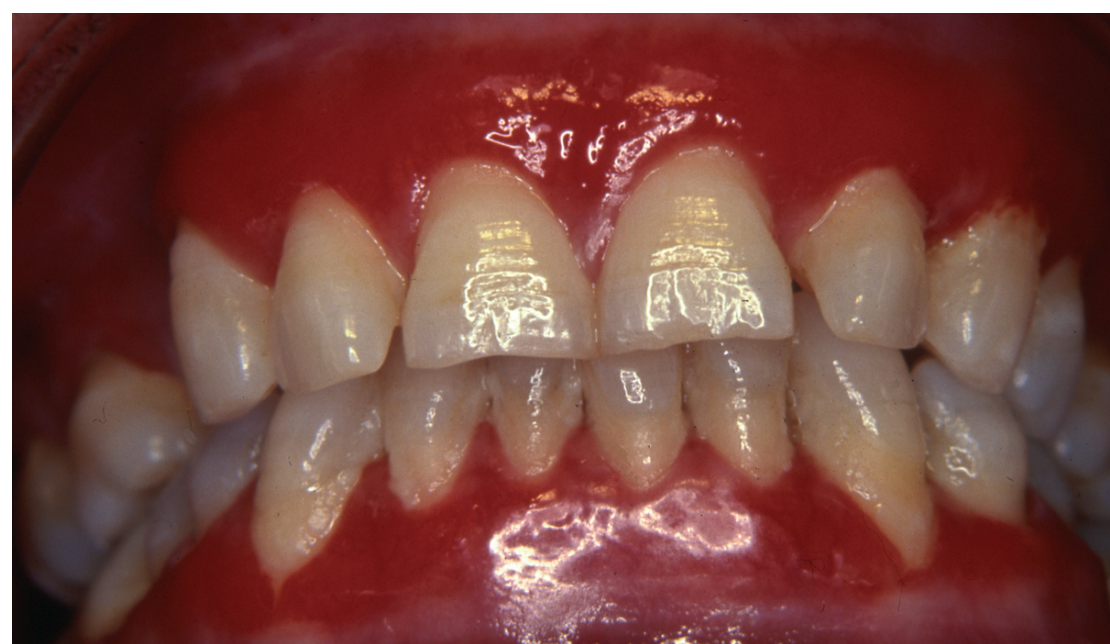

Figura 1. Aspecto clínico de una gingivitis descamativa crónica en la que se puede observar eritema generalizado relacionado con la pérdida de epitelio.

alteraciones gingivales de origen genético o fibromatosis gingival hereditaria.

\section{Allereciociones gingiales}

\section{relacionadas con enfer- medades mucocutáneas}

\section{Gingivitis descamativa cró- nica (GD)}

La GD es una de las principales alteraciones gingivales no relacionadas con placa. Hoy en día debe considerarse como una manifestación clínica de diferentes enfermedades mucocutáneas crónicas tales como el liquen plano (LP), el penfigoide de las mucosas (PM) o el pénfigo vulgar (PV), principalmente, aunque también puede darse en otras patologías menos frecuentes como la enfermedad por IgA lineal, la estomatitis ulcerativa crónica, la epidermolisis ampollar adquirida, el penfigoide bulloso, la disquera- tosis congénita, la estomatitis de contacto, la dermatitis herpetiforme, el lupus eritematoso o la psoriasis.

Se trata de un signo clínico de evolución crónica con periodos de remisión y exacerbación, caracterizado por un eritema difuso de la encía insertada en las zonas dentadas, más frecuentemente por vestibular que por palatino, que se asocia con un área de descamación del epitelio pudiendo observarse, con el avance de la lesión, una descamación espontánea del epitelio y zonas de erosión con sangrado y dolor moderado o intenso (fig.1). Suele darse en personas mayores de 40 años y presenta predilección por el sexo femenino.

El interés de esta patología se debe a su frecuencia relativamente elevada, a que puede confundirse con otros tipos de gingivitis relacionadas con placa y a que puede ser la manifestación de procesos sistémicos subyacentes, algunos de los cuales presentan una importante morbilidad e incluso mortalidad. 


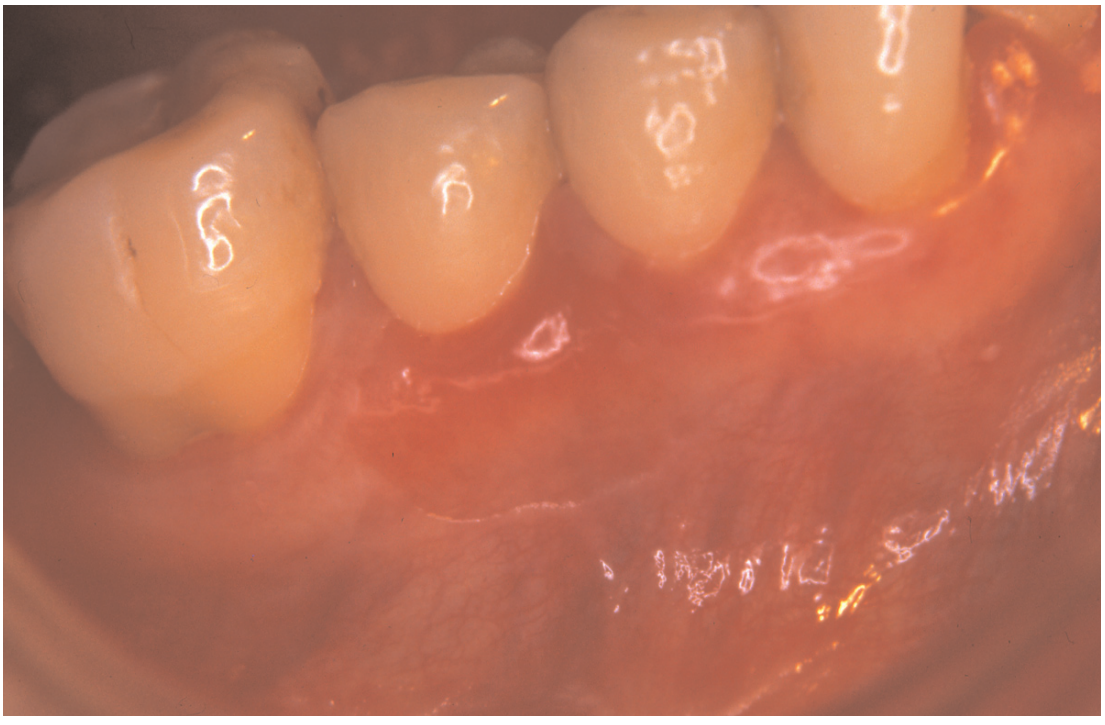

Figura 2. Ampolla a nivel gingival como manifestación de un liquen plano oral.

A continuación se describen algunas de las enfermedades mucocutáneas relacionadas con la $\mathrm{CD}$.

\section{Liquen plano (LP)}

Se trata de una de las enfermedades mucocutáneas crónica mediada inmunológicamente más frecuente. Las manifestaciones orales aparecen, aproximadamente, en un $2 \%$ de la población general, principalmente a partir de los 30 años y con predilección por el sexo femenino, mientras que las lesiones cutáneas aparecen en un $0,4 \%{ }^{1}$.

Las lesiones cutáneas consisten en pequeñas pápulas, rojizas o violáceas, pruriginosas en las superficies de flexión de las extremidades.

En la cavidad oral se distinguen dos patrones diferentes de LP que pueden manifestarse simultáneamente: el patrón reticular se caracteriza por la presencia de líneas blanquecinas, hiperqueratósicas, denominadas estrías de Wickham que se entrecruzan y que asientan, principalmente, en la zona posterior de la mucosa yugal generalmente de modo bilateral. Este tipo de lesiones no suele producir sintomatología y no requiere tratamiento. El otro patrón es el atrófico-erosivo, que consiste en zonas de mucosa atrófica, cen sobre todo en la mucosa yugal, los fondos de vestíbulo, el dorso de la lengua y en la encía pudiendo manifestarse como CD (fig.2). Suelen cursar con dolor y requerir tratamiento nido de triamcinolona $0,1 \%$ en orabase o suspensión oral, propionato de clobetasol $0,025 \%$ o fluocinolona $0,1 \%$.

En ocasiones el liquen plano aparece asociado a la hepatitis $C$, aunque también hay estudios, no siempre consensuados, que lo relacionan con otras alteraciones sistémicas como la hepatitis B, la hipertensión arterial o la diabetes mellitus'.

En el examen histopatológico se erosiones o ulceraciones que aparecon corticoides tópicos como acetó- observa degeneración hidrópica de la capa basal con un denso infiltrado inflamatorio subepitelial en banda consistente, principalmente, en linfocitos $T$ y con frecuencia también pueden observarse queratinocitos degenerados en la interfase epitelio-conectivo. La inmunofluorescencia directa (IFD) demuestra depósito lineal o granular de fibrinógeno en la membrana basal.

Debido a la controversia que existe en cuanto al potencial de transformación maligno de estas lesiones, especialmente las formas atrófico-erosivas, deben ser controladas periódicamente.

\section{Penfigoide de las mucosas (PM)}

También conocido previamente como penfigoide cicatricial, es una enfermedad crónica autoinmune de carácter vesiculoampolloso que afecta, principalmente, a la mucosa de la cavidad oral aunque también pueden verse afectadas otras mucosas como la conjuntiva, la nasal, la esofágica, la laríngea, la vaginal o la rectal, apareciendo afectación cutánea con una frecuencia mucho menor. Esta enfermedad aparece más frecuentemente entre los 50 y 70 años y presenta predilección por el sexo femenino.

Los hemidesmosomas de la zona de la membrana basal están formados por diferentes moléculas que pueden actuar como autoantígenos en el desarrollo de esta patología, siendo la laminina 5 , las integrinas $\alpha 6$ y $\beta 4$ y el antígeno 2 del pénfigo bulloso los que parecen estar presentes en el $\mathrm{PM}^{2 * *}$.

La cavidad oral suele ser el primer lugar afectado y la encía es la localización preferente donde se pueden observar las lesiones vesículoampollo- 


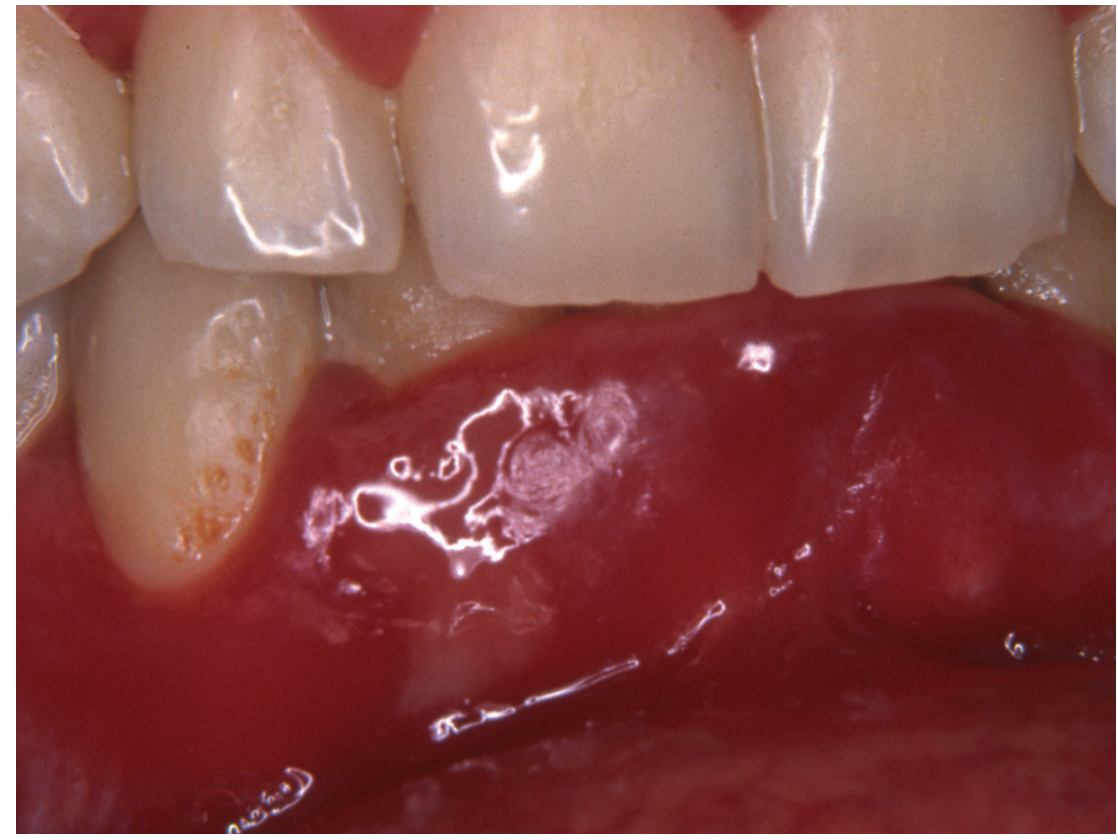

Figura 3. Las ampollas subepiteliales en el penfigoide de las mucosas se rompen dando lugar a erosiones gingivales.

sas, GD y ulceraciones que tienden a curar sin dejar cicatriz (fig.3). Sin embargo las lesiones oculares, que pueden afectar entre el 11 y el 61\% de los pacientes de PM1', pueden Ilegar a provocar adherencias entre la conjuntiva bulbar y la palpebral (simblefaron) que si no se tratan puede dar lugar a entropión, triquiasis y en última instancia a ceguera.

Para el estudio histopatológico y de inmunofluorescencia la biopsia debe tomarse de áreas perilesionales tratando de conservar intacto el epitelio. El examen histológico revela la presencia de ampollas subepiteliales, siendo el epitelio, con todas sus capas, el techo de la misma mientras que la base está formada por el tejido conectivo en el que puede observarse infiltrado inflamatorio crónico no específico de carácter moderado.

Con IFD, en el $90 \%$ de los casos, se detecta depósito lineal de IgC y C3 a lo largo de la membrana basal aunque también pueden identificarse IgM e IgA. La IFI tan solo resulta positiva en el $5 \%$ de los $\operatorname{casos}^{3}$ por lo que su valor diagnóstico es escaso.

El tratamiento consiste en la aplicación tópica de corticoides como el acetónido de triamcinolona, fluocinoIona o propionato de clobetasol varias veces al día aunque si las lesiones no mejoran y en caso de afectación ocular o cutánea se debe emplear tratamiento sistémico con prednisona 60 80 mg/día solos o asociados a azatioprina o ciclofosfamida 3 . También se han logrado buenos resultados con tetraciclina sola o combinada con niacinamida1. Además, en el manejo de estas lesiones, el control de la placa bacteriana y de los irritantes locales es de gran importancia. Ante un diagnóstico de PC, a parte del tratamien- to oral, será necesario remitir al paciente a un oftalmólogo con el fin de prevenir las lesiones oculares.

\section{Pénfigo Vulgar (PV)}

Es otra enfermedad autoinmune, de evolución crónica con periodos de remisión y exacerbación, de carácter vesiculoampolloso en la que se producen anticuerpos contra la desmogleína 1 y 3, que son moléculas de adhesión intracelular de los desmosomas, liberándose, como resultado de la reacción antígeno-anticuerpo, una proteasa que produce la ruptura de las uniones de las células del epitelio (acantolisis) dando lugar a la formación de ampollas intraepiteliales en la piel y las mucosas. Se ha demostrado que cuando existe afectación oral la mayoría de los anticuerpos creados actúan contra la desmogleína $3^{4}$, por lo que se piensa que éste es el principal antígeno en el PV con manifestaciones orales. Se trata de una enfermedad poco frecuente que aparece sobre todo entre los 40 y 60 años sin predilección por ningún sexo y parece ser más frecuente entre judíos y en toda el área del Mediterráneo ${ }^{3}$. Las principales lesiones mucosas se dan en la cavidad oral y la faringe; si bien cualquier otra mucosa del organismo puede verse también afectada. En el $60-70 \%$ de los casos de PV las primeras lesiones aparecen en la boca y en el $100 \%$ de los casos aparecen lesiones orales en el transcurso de la enfermedad en forma de ampollas que se rompen rápidamente dando lugar a erosiones dolorosas de la mucosa en cualquier localización (sobre todo el paladar blando, la mucosa labial, la yugal y la superficie ventral de la lengua). En la encía estas lesiones suelen 
adoptar las características de GD por lo que podría confundirse con otro tipo de gingivitis relacionada con placa cuando ésta es la única manifestación del PV.

Las lesiones cutáneas consisten en grupos de ampollas en cualquier localización que se rompen dejando áreas de dermis expuesta, siendo un hallazgo característico de esta enfermedad, el signo de Nikolsky (aparición de ampollas en la piel al ejercer presión lateralmente).

Para el diagnóstico de esta lesión es necesario el estudio histopatológico y de inmunofluorescencia. En el primero se pueden observar ampollas intraepiteliales en las que el techo de las mismas está formado por las capas superiores del epitelio mientras que el suelo lo forma la capa basal del mismo que permanece unida a la membrana basal. Las células del estrato espinoso pierden cohesión entre ellas adoptando una forma redondeada (células de Tzanck) y en el tejido conectivo subyacente puede observarse infiltrado inflamatorio crónico leve o moderado. Con IFD se pueden detectar IgG, fundamentalmente, aunque también IgM y C3 en los espacios intercelulares de las células epiteliales, y la IFI resulta positiva en el $80-90 \%$ de los casos pudiendo demostrarse la presencia de anticuerpos circulantes en el suero de estos pacientes.

Ante un caso de PV el paciente debe ser derivado urgentemente al dermatólogo con el fin de iniciar la terapia adecuada. Hasta la aparición de los corticoides esta enfermedad presentaba un curso letal y los pacientes fallecían por desequilibrio electrolítico o por infecciones secundarias. Hoy en día para el tratamiento se emplean corticoides sistémicos, especialmente la prednisona, asociada con fármacos inmunosupresores como la azatioprina que, una vez controlada la enfermedad, permiten disminuir la dosis de corticoides disminuyendo así los efectos secundarios de los mismos. Otros fármacos que también han demostrado algún efecto son la dapsona y la ciclosporina $A^{1}$.

\section{Lupus eritematoso (LE)}

Es otra alteración de carácter autoinmune y etiología desconocida en la que se han encontrado numerosos factores que pueden estar relacionados como la predisposición genéti$\mathrm{ca}$, los factores ambientales (agentes infecciosos, estrés, dieta y exposición a tóxicos), las alteraciones hormonales e inmunológicas y los agentes físicos como la exposición solar. Clásicamente se han descrito dos variantes de LE: el LE sistémico (LES) y el lupus eritematoso discoide (LED). En el LES puede aparecer fiebre crónica, pérdida de peso, síntomas de artritis, serositis, enfermedades neurológicas, manifestaciones inmunológicas, enfermedades mucocutáneas (erupción en alas de mariposa en la zona malar, fotosensibilidad y úlceras orales), alteraciones hematológicas y alteraciones renales. Las manifestaciones orales están presentes hasta en el $75 \%$ de los casos, siendo las más frecuentes la hiposilia, las úlceras orales, la boca ardiente, la enfermedad periodontal y las alteraciones de la ATM hasta en un $60 \%$ de los casos $^{5}$.

EI LED presenta lesiones en la piel y las mucosas. Las lesiones orales se caracterizan por una erosión o ulceración central eritematosa rodeada de un halo blanco y estrías queratósicas irradiando desde el mismo, preferen- temente en la encía, la mucosa yugal y la mucosa labial. Las lesiones cutáneas pueden aparecer en forma de placas discoides en la cara y el cuero cabelludo, alopecia o lesiones vesículoampollosas. En el examen histopatológico se observa vacuolización de queratinocitos, depósito PAS+ subepitelial, edema de la lámina propia e infiltrado linfocitario perivascular'. Con IFD se detectan depósitos granulares de IgM, IgG, IgA, C3 y fibrinógeno en la zona de la membrana basal. Tanto las lesiones orales como las cutáneas suelen responder bien al tratamiento tópico con corticoides solo o combinado con otros agentes inmunosupresores como la ciclofosfamida, si bien en los casos más severos puede ser necesario el uso de corticoides sistémicos. También se han observado buenos resultados con antimaláricos, retinoides tópicos o sistémicos, sales de oro y ciclosporina'.

\section{Psoriasis}

Es una enfermedad mucocutánea crónica de carácter inflamatorio que produce lesiones, localizadas o generalizadas, en forma de pápulas eritematosas con una cubierta hiperqueratósica blanca en los codos, las rodillas y el cuero cabelludo. Las lesiones intraorales son poco frecuentes y pueden ir desde lesiones eritematosas irregulares de bordes blanco-amarillentos a verdaderas ulceraciones y $\mathrm{CD}$. Las lesiones que afectan a la encía pueden comprometer el estado periodontal del paciente. Histológicamente se puede observar adelgazamiento del epitelio e infiltrado linfocitario crónico y, frecuentemente, también se observan microabscesos papilares con polimorfonucleares. 


\section{Alleraciones gingivales relacionadas con niveles hormonales}

Las hormonas sexuales actúan como factor etiológico coadyuvante, siendo la gingivitis del embarazo y el granuloma piógeno las principales alteraciones que aparecen en la encía.

\section{Gingivitis del embarazo}

La gingivitis durante el embarazo no se diferencia mucho de la gingivitis por placa ${ }^{6}$; los cambios inflamatorios comienzan desde el segundo mes de embarazo y consisten en una inflamación no específica, en la que se produce un aumento de la vascularización y fenómenos proliferativos con gran cantidad de infiltrado de células inflamatorias. La encía aparece de color rojo oscuro y sangra fácilmente $y$, además, existe edema, adelgazamiento del margen gingival e incluso puede existir hiperplasia de las papilas interdentarias con formación de pseudobolsas.

Se debe tener en cuenta que a nivel gingival existen receptores para estrógenos y progesterona lo que permite que estas hormonas puedan ejercer diferentes efectos sobre el tejido gingival ${ }^{7}$ entre los que se encuentran alteraciones vasculares, celulares, microbiológicas e inmunológicas que dan lugar a un aumento del grado de gingivitis. Por tanto, el desarrollo y el mantenimiento de gingivitis y periodontitis durante el embarazo pueden explicarse por las variaciones hormonales; sin embargo en ausencia de placa bacteriana estos

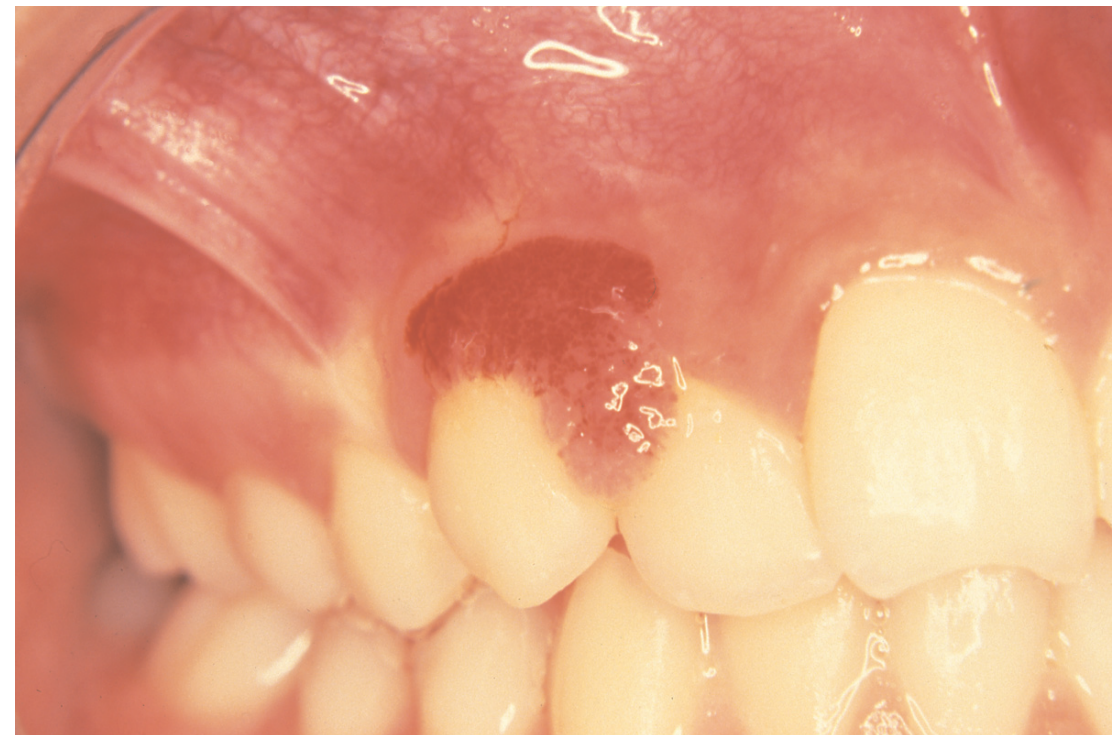

Figura 4. Granuloma piógeno en la encía vestibular en el que se puede observar la proliferación de vasos sanguíneos característica de esta lesión.

cambios no son capaces de dar lugar a enfermedad periodontal.

\section{Granuloma piógeno}

se trata de una lesión exofitica, sesil o pediculada, que aparece, fundamentalmente, en la encía vestibular y que sangra fácilmente debido a la excesiva vascularización que se desarrolla (fig.4). El principal factor etiológico es la presencia de placa bacteriana aunque también pueden aparecer relacionados otros factores.

El granuloma gravídico o granuloma piógeno que se desarrolla durante el embarazo es igual que el granuloma piógeno no relacionado con niveles hormonales ${ }^{6}$. Su diámetro no suele ser mayor de $2 \mathrm{~cm}$ y generalmente es indoloro aunque en ocasiones la superficie pueda aparecer ulcerada.

Histopatológicamente se caracteriza por una proliferación de vasos sanguíneos asociada a inflamación. Además de la placa bacteriana pueden estar relacionados otros factores locales como traumatismos, o sistémicos como las alteraciones en los niveles hormonales que se producen durante el embarazo. Las hormonas sexuales femeninas no sólo actúan aumentando directamente el nivel de factores angiogénicos, si no que además protege a los macrófagos activados (responsables de la producción de factores angiogénicos), de los mecanismos de apoptosis $8^{8 *}$.

Esta lesión está presente en el 5\% de las mujeres durante el embarazo y puede desarrollarse en cualquier momento del mismo, si bien lo más frecuente es que aparezca durante el primer o segundo mes del primer embarazo y suele desaparecer espontáneamente tras el parto si se eliminan los irritantes locales. En caso de ser necesaria la excisión quirúrgica, suele hacerse después del parto y solo se realiza durante el embarazo si causa alteraciones funcionales importan- 
tes o presenta sangrado profuso, aunque suele recidivar hasta que el embarazo finaliza.

\section{Alleraciones gingivales relacionadas con fármacos}

En los países desarrollados la esperanza de vida ha aumentado y la población, en general, alcanza edades más avanzadas con un estado de salud aceptable; si bien esto es conseguido a expensas de la administración de un gran número de fármacos. Además continuamente están apareciendo en el mercado nuevas categorías de medicamentos. Todo esto hace que la prevalencia de lesiones orales relacionadas con la administración de fármacos esté aumentando. Entre estas lesiones podemos encontrar alteraciones gingivales como las reacciones liquenoides y las hiperplasias gingivales.

\section{Reacciones liquenoides ${ }^{9}$}

Las reacciones liquenoides y el LP presentan una clínica y unos hallazgos histopatológicos similares, lo que hace difícil el diagnóstico diferencial; sin embrago en las reacciones liquenoides se encuentra asociación entre la administración de algún fármaco, el contacto con algún metal o alimento o la presencia de alguna patología sistémica subyacente, por lo que el control de estos factores suele lograr la resolución de las lesiones.

\section{Hiperplasias gingivales (HG)}

La HG inducida por fármacos fue descrita por primera vez en 1939 aso- ciada a la administración crónica de un fármaco antiepiléptico; la fenitoína ${ }^{10}$. Posteriormente se ha visto también asociada a la ciclosporina, un inmunosupresor utilizado en los pacientes con transplante de órganos entre otros, y el nifedipino, un bloqueante de los canales de calcio ${ }^{11}$.

Clinica e histológicamente los tres tipos son similares y se presentan en el $50 \%$ de los pacientes en tratamiento con fenitoína, en el 30\% con ciclosporina y en el $20 \%$ con nifedipino, apareciendo más frecuentemente en niños y jóvenes a partir del tercer mes de tratamiento cuando se ha alcanzado la suficiente concentración del fármaco en los tejidos gingivales ${ }^{12^{*}}$. El sector anterior es el lugar más comúnmente afectado aunque puede aparecer de modo generalizado y está siempre en relación con zonas dentadas. La hiperplasia aparece, característicamente, en la encía marginal, con una superficie lobulada, sin tendencia al sangrado, que puede llegar a cubrir por completo las coronas dentarias.

Se considera que es una alteración multifactorial en cuyo desarrollo pueden influir la edad del paciente, la predisposición genética, la dosis administrada, la duración del tratamiento, los niveles plasmáticos alcanzados, la placa bacteriana y la existencia previa de afectación gingival o periodontal ${ }^{11,12^{\star}}$. La HC se debe a un aumento en la cantidad de colágeno y de componentes no colágenos de la matriz extracelular entre los que se encuentran, principalmente, los glucosaminoglucanos y los proteoglucanos. El mecanismo por el que se produce este aumento es debido a un aumento en la producción de colágeno, una disminución de su degradación y, recientemente, también se han visto implicados factores de crecimiento entre los que destaca el factor de crecimiento de los queratinocitos que ha sido descrito in vivo en las HG debidas a ciclosporina ${ }^{13^{*}}$.

La interconsulta con el médico que controla a estos pacientes puede ser necesaria con el fin de ajustar la dosis del fármaco o sustituirlo por otro de distinto grupo químico con el mismo efecto terapéutico pero que no provoque HG como efecto secundario, siempre que esto sea posible.

Algunos pacientes responden bien al tratamiento periodontal no quirúrgico; sin embargo en muchos casos es necesaria la realización de gingivectomías a bisel externo para eliminar el tejido, aunque las recurrencias tras este tratamiento son frecuentes.

\section{Alleraciones gingivales relacionadas \\ con infecciones viricas}

Está ampliamente aceptado que tanto la gingivitis como la periodontitis están causadas por las bacterias presentes en el biofilm que coloniza las superficies dentarias. Sin embargo, recientemente se ha sugerido que determinados virus podrían tener influencia en el desarrollo y en la severidad de las alteraciones periodontales. La mayoría de los virus que causan alteraciones gingivales y periodontales son virus ADN entre IOS que se encuentran el virus de la inmunodeficiencia humana (VIH) y los herpesvirus ${ }^{14}$. 


\section{Alteraciones relacionadas con el VIH/ Sida}

EI VIH/Sida debe encuadrarse entre las enfermedades infectocontagiosas, siendo su agente causal un retrovirus de la familia de los Lentivirus que ha recibido el nombre de VIH (virus de la inmunodeficiencia humana). Los linfocitos TCD4+ y los macrófagos constituyen el blanco principal de este virus. En la actualidad el sida es la cuarta causa de mortalidad en todo el mundo y la primera en África subsahariana; si bien, en los países en los que está disponible la terapia antirretroviral de modo generalizado, especialmente la de gran actividad (TARGA), se ha producido una importante disminución de la incidencia y de la mortalidad asociada al sida, lo que ha provocado que la infección por VIH se esté convirtiendo en una enfermedad crónica, que genera mayores demandas de cuidados sanitarios, entre los que deberían estar incluidos siempre la atención bucodental, ya que las lesiones orales asociadas al sida son un componente fundamental en la progresión de la enfermedad y ocurren en un $30-80 \%$ de los pacientes afectados $^{15}$

Solamente existen tres presentaciones clínicas de enfermedad periodontal características de los pacientes infectados por VIH (fig.5) que se diferencian, únicamente, por la zona afectada: el eritema gingival lineal (EGL), la gingivitis ulcerativa necrotizante (GUN) y la periodontitis ulcerativa necrotizante (PUN).

El eritema gingival lineal (EGL) se presenta como una banda rojiza a lo largo del margen gingival, y puede estar acompañado o no de sangrado y molestias. Aparece asociado más fre-

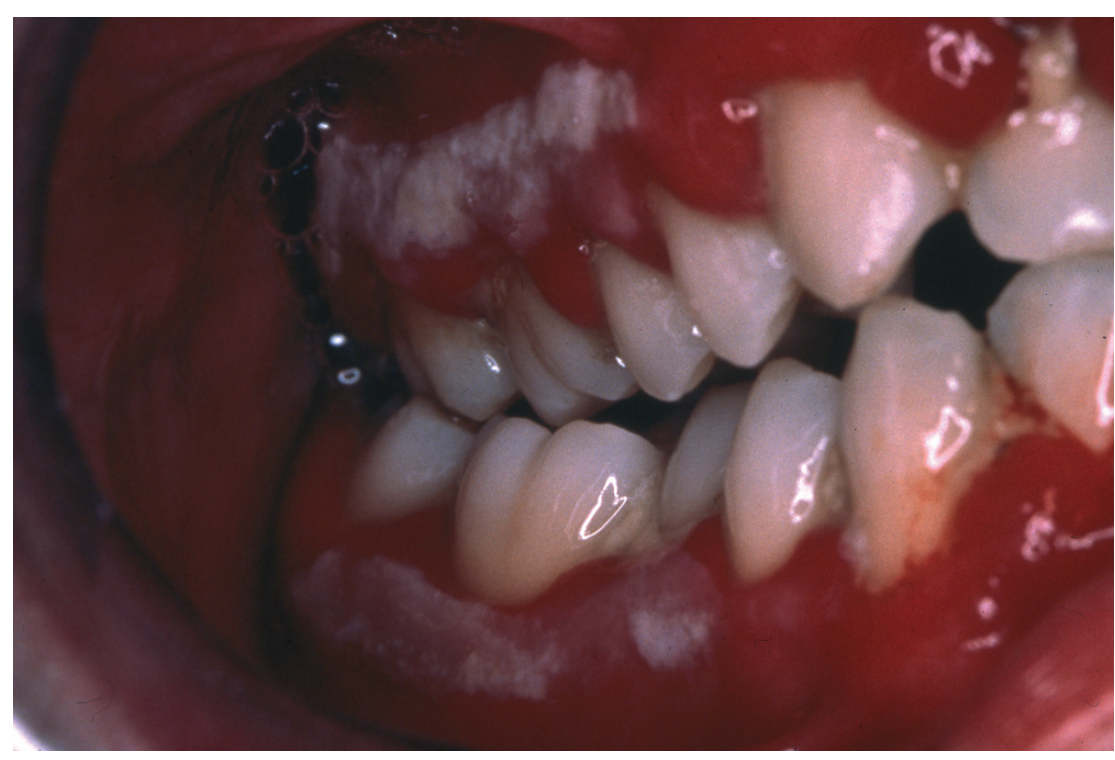

Figura 5. Paciente VIH+ con alteraciones gingivoperiodontales y lesiones típicas de candidiasis pseudomembranosa en la encía vestibular.

cuentemente a los dientes anteriores, aunque también se puede extender a los sectores posteriores. Algunos estudios indican que existe una relación entre la colonización subgingival de especies Cándida y la aparición de lesiones periodontales relacionadas con el $\mathrm{VIH}$, incluyendo el $\mathrm{EGL}^{14}$. No responde bien a los medios de control de placa, ni al raspado y alisado radicular; sin embargo no se deben descuidar las medidas de higiene y profilaxis acompañándolas con irrigaciones de gluconato de clorhexidina al 0,12 o $0,2 \%$, o povidona yodada al $10 \%$ dos veces al día durante dos semanas ${ }^{15}$.

La gingivitis ulcerativa necrotizante (GUN) es un signo temprano y frecuente en sujetos infectados por $\mathrm{VIH}$, con un índice de prevalencia del 4-16\% y que afecta en mayor proporción a varones homosexuales. Se caracteriza por una encía enrojecida con inflamación difusa, existiendo además afectación de la papila inter- dental (necrosis) y del margen gingival (fig.6), llegando incluso a dejar zonas de hueso expuestas por la pérdida de tejidos blandos. El cuadro se acompaña, además, de dolor, "faetor ex ore» (halitosis), sialorrea intensa y hemorragia espontánea o tras el cepillado.

La periodontitis ulcerativa necrotizante (PUN) se presenta de una forma mucho más agresiva en los pacientes $\mathrm{VIH}+$ que en la población seronegativa, con una prevalencia mayor entre los hombres homosexuales y bisexuales. Se produce una destrucción importante de los tejidos periodontales y del hueso acompañada de dolor intenso, y en algunos casos estas lesiones pueden parecerse a las causadas por citomegalovirus 0 por linfoma no-Hodgkin ${ }^{16}$. En el $95 \%$ de los pacientes con PUN los niveles TCD4+ son menores de 100 células $/ \mathrm{mm}^{3}$, por lo que es un marcador clínico de una inmunosupresión severa. Además tiene también valor pro- 
nóstico, ya que cuando aparece la enfermedad, la mortalidad a los 18 meses se aproxima al $60 \%$.

En caso de gran depleción del sistema inmune este cuadro puede evolucionar a una estomatitis necrotizante, caracterizada por una exposición ósea y por la presencia de secuestros que recuerdan al noma o cancrum oris ${ }^{15,16}$.

El tratamiento para la GUN y PUN consiste en raspado y alisado radicular, al que se deben asociar irrigaciones con clorhexidina al 0,12\% o con povidona yodada al 10\%. Además se debe iniciar tratamiento antibiótico durante una semana siendo de elección el metronidazol 250 mg-500 mg 4 veces/día, aunque si existe hepatopatía debe usarse la amoxicilina/ácido clavulánico a dosis de 500/125 o 875/125 mg 3 veces/día o la clindamicina 150 mg 4 veces/día ${ }^{15,16}$.

\section{Alteraciones relacionadas con herpesvirus humanos (VHH)}

Generalmente la infección por estos virus ocurre en la infancia a través de secreciones como la saliva. Se han identificado ocho tipos de herpesvirus humanos (VHH) que se dividen en tres familias en función del tipo de células que infectan y las propiedades de replicación: los herpesalfa presentan un patrón de replicación rápido y permanecen latentes en los ganglios sensoriales. Aquí se incluyen el virus del herpes simple 1 y 2 (VHS-1 y 2; VHH-1 y 2) y el virus varicela-zoster ( $\mathrm{VVZ}$; VHH-3); el grupo de herpes-beta, que está formado por citomegalovirus (CMV; $\mathrm{VHH}-5$ ) y por los virus del herpes humano 6 y 7 (VHH-6 y 7) se caracterizan por una

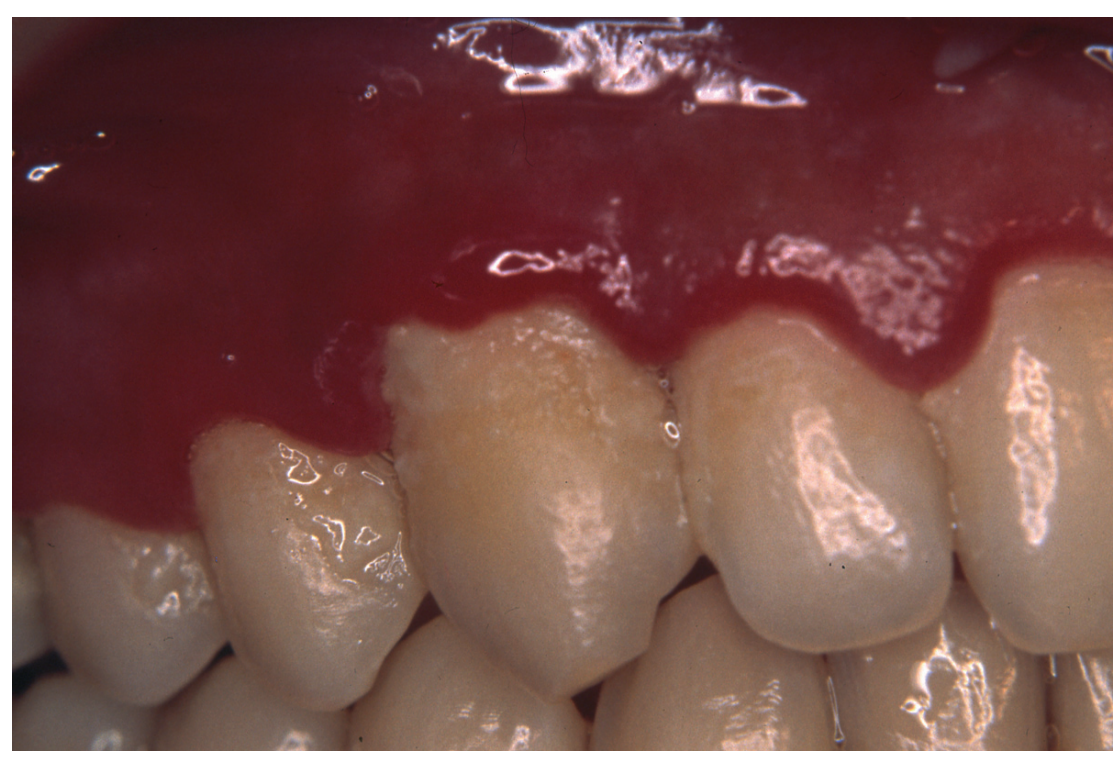

Figura 6. Paciente VIH+ con lesiones típicas en los cuadros de GUN.

replicación lenta, por la producción de células multinucleadas y la latencia que se produce en el tejido linforreticular, las glándulas secretorias y los riñones. Por último los herpes-gamma, que incluyen el virus de EpsteinBarr (VEB; VHH-4) y el virus del herpes humano 8 (VHH-8), infectan linfocitos B o T aunque también las células epiteliales y los fibroblastos. En este grupo la latencia se produce en el tejido linfoide ${ }^{14}$.

\section{- VHS-1 y 2/VHH-1 y 2}

La infección por estos virus presenta una distribución mundial y afecta generalmente a la piel y las mucosas, aunque también puede aparecer afectación oftálmica, neurológica, y más raramente afectación sistémica. El VHS-1 es transmitido por contacto directo (a través de besos por ejemplo), o indirectamente a través de instrumental infectado o manos, produciéndose manifestaciones orofaciales 0 neurológicas, mientras que el VHS-2 se transmite por vía sexual y da lugar a lesiones genitales, si bien ambos tipos pueden ser detectados tanto en infecciones orofaciales como genitales ${ }^{14,17^{*}}$.

La primoinfección suele ocurrir en la infancia a través de saliva infectada o por contacto directo con las lesiones, dando lugar a una respuesta inmunitaria mediada celularmente en el epitelio infectado. Posteriormente se produce la replicación en las células epiteliales y algunas de las partículas infectivas ascienden, retrógradamente, a través de las fibras sensitivas hasta los ganglios correspondientes donde permanecen latentes hasta que algún agente como la inmunosupresión, el estrés, los traumatismos, la menstruación, la exposición a radiación ultravioleta o la fiebre produce su reactivación dando lugar a las formas recurrentes ${ }^{14}$.

La primoinfección herpética suele darse en niños de 1 a 5 años, siendo 


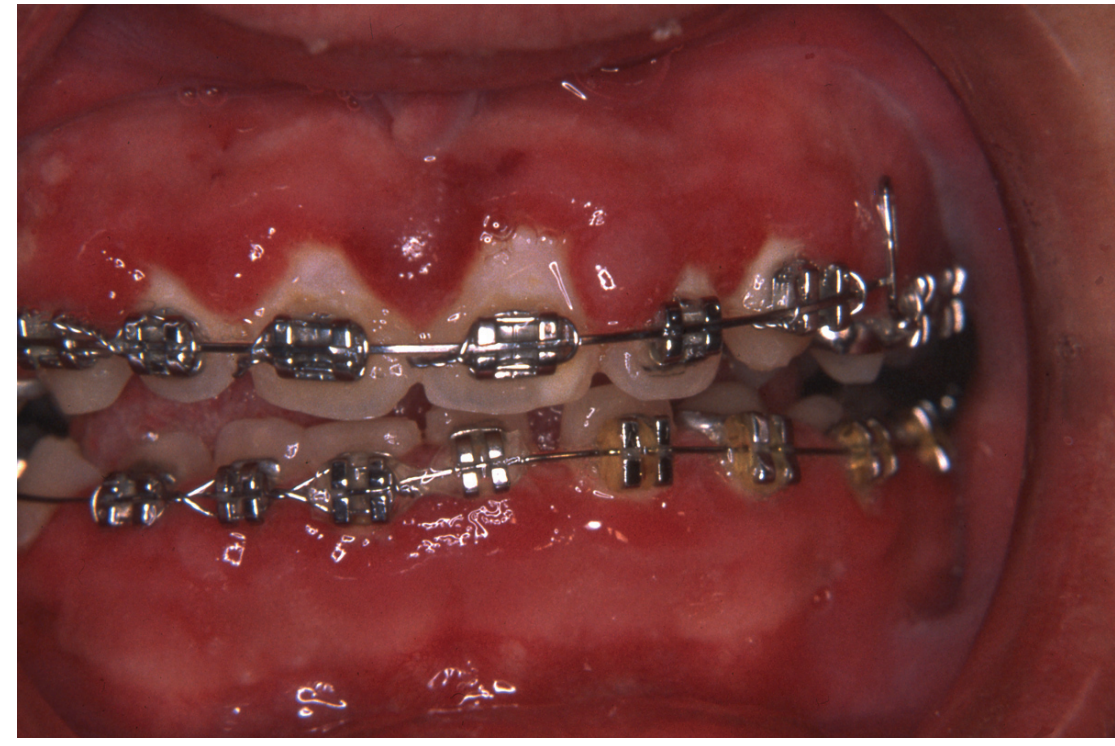

Figura 7. Primoinfección herpética con un cuadro de gingivitis en el que se pueden observar vesículas y erosiones gingivales.

la alteración gingival de origen vírico más común, aunque generalmente es asintomática. Cuando se producen manifestaciones constan de una fase prodrómica con fiebre entre $39-40^{\circ} \mathrm{C}$, malestar general, inapetencia, decaimiento y adenopatías grandes, dolorosas y no adheridas a planos profundos, en el territorio submandibular o incluso cervical lateral. Después de 5 días aparece un cuadro de gingivitis generalizada, por vestibular y palatino de ambas arcadas, en la que se puede observar una encía eritematosa y edematosa con hemorragia frecuente ante pequeños estímulos. Posteriormente aparecen vesículas de $2-4 \mathrm{~mm}$ de diámetro, dolorosas en la encía, la región peribucal, el paladar duro y blando, la lengua y los labios, que se rompen dejando erosiones y ulceraciones cuyo fondo está recubierto por una pseudomembrana amarillenta o grisácea rodeada de un halo rojo intenso, no solo en la encía si no por toda la mucosa oral (fig.7). El proceso tiene un curso autolimitado produciéndose la curación de manera progresiva y espontánea en un plazo de 15 días $^{18}$

El herpes recidivante puede aparecer de dos formas: la forma labial y la intraoral. La forma intraoral es más común de lo que se piensa ya que con frecuencia son diagnosticadas como aftas $^{18}$, aunque estas lesiones asociadas a herpes aparecen en la mucosa queratinizada, mientras que las aftas son típicas de las zonas no queratinizadas. Se trata de lesiones vesiculares que se rompen fácilmente dando lugar a erosiones, no mayores de un cm de diámetro, en la encía y el paladar duro que curan espontáneamente entre 7 y 10 días, aunque en pacientes inmunodeprimidos la reactivación del virus puede dar lugar a un cuadro atípico con lesiones más extensas, agresivas y dolorosas, que evolucionan más lentamente.
También se ha señalado al VHS-1 como agente etiológico de algunas recesiones gingivales. Éstas se diferencian de las relacionadas con la enfermedad periodontal y con el trauma por cepillado en que progresan más rápidamente dando lugar a una destrucción importante de tejido gingival asociada a dolor, fiebre y linfadenopatías ${ }^{19}$.

\section{Alleraciones gingivales relacionadas con discrasias sanguineas}

\section{Leucemia}

La leucemia es una enfermedad maligna caracterizada por un marcado aumento en el número de leucocitos y precursores de los mismos en la sangre, unido a una proliferación del tejido linfático del bazo, la médula ósea y los ganglios. Según la evolución se pueden distinguir las leucemias agudas y los procesos mieloproliferativos crónicos entre los que se encuentran las leucemias crónicas. Las manifestaciones orales son frecuentes y en ocasiones constituyen un signo temprano que puede ayudar en el diagnóstico precoz. La encía, debido a que presenta predisposición al infiltrado por células leucémicas, suele ser uno de los lugares más afectados pudiendo aparecer inflamación intensa y aumento del volumen (fig.8), especialmente en la leucemia monocítica, en ausencia de irritantes locales como la placa o los traumatismos. También puede aparecer hemorragia gingival debido a la trombocitopenia. 


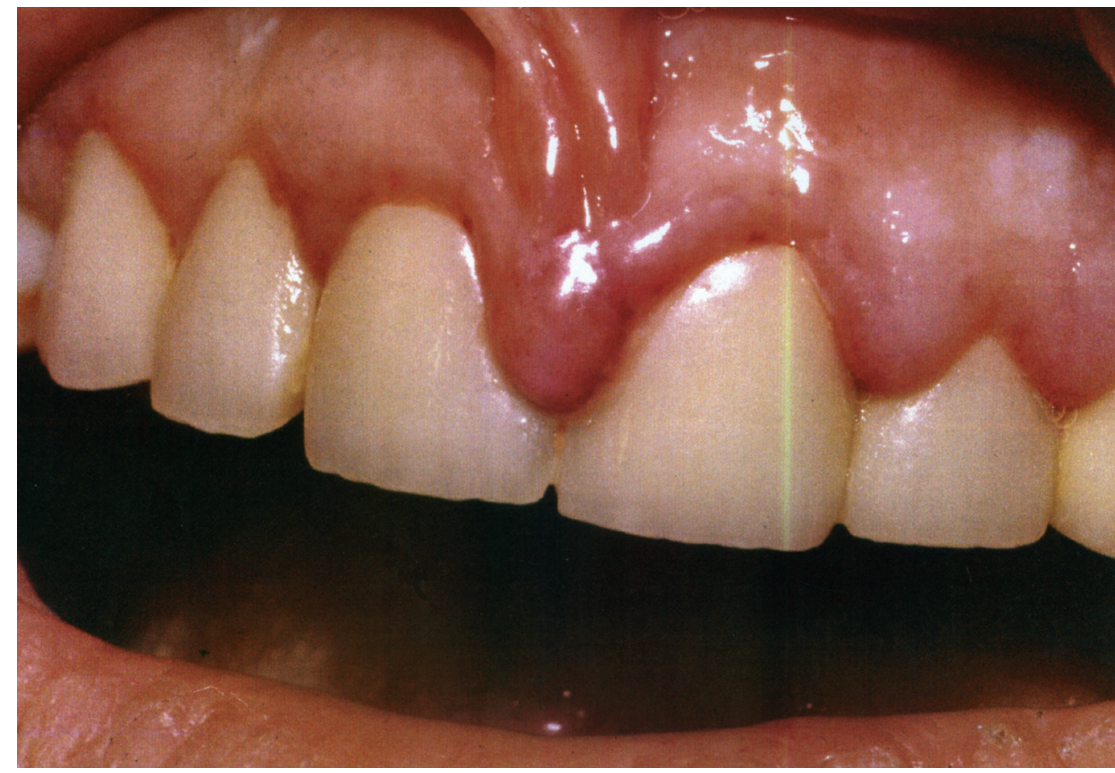

Figura 8. Las lesiones gingivales representaron, en este caso, el primer signo de una leucemia.

Histológicamente en las lesiones gingivales se puede observar, en mayor o menor grado infiltrado de células inflamatorias e infiltrado de células leucémicas ${ }^{20}$.

\section{Síndromes mielodisplási- cos}

Otras discrasias sanguíneas relacionadas con la leucemia son los síndromes mielodisplásicos (SMD) que constituyen un grupo raro de alteraciones hematológicas de las células de la serie mieloide. Son un grupo heterogéneo y se cree que algunas de ellas son parte del mismo espectro de alteraciones hematopoyéticas las cuales, pueden transformarse en leucemia mieloide aguda (LMA) hasta en un 20 $-25 \%$ de los casos ${ }^{21}$. Cursan con anemia en el $90 \%$ de los casos y la mayoría presenta también neutropenia y trombocitopenia ${ }^{22}$. La edad de aparición más frecuente es a partir de los
60 años con una marcada predilección por el sexo masculino ${ }^{21}$.

La clasificación FAB (French-American-British classification) divide estas alteraciones en: anemia refractaria sin exceso de blastos (AR), anemia refractaria con exceso de blastos (AREB), anemia refractaria sideroblástica (ARS) y leucemia mielomonocítica crónica $\left(\mathrm{LMMC}^{22}\right.$

Las complicaciones orales son frecuentes debido a las alteraciones cuantitativas y cualitativas de la sangre y a los agentes quimioterápicos utilizados para el tratamiento de la MDS, pudiendo estar presentes entre el 15 y el $85 \%$ de los pacientes.

En encía puede aparecer hemorragia espontánea, hiperplasia gingival y ulceraciones. Además pueden aparecer otros signos y síntomas orales como parestesias, petequias y herpes labial e intraoral persistente debido a la neutropenia ${ }^{22}$.

\section{Neutropenia severa congé- nita (NSC)}

La NSC, conocida también como Síndrome de Kostmann, es una alteración genética que se transmite de forma autosómica recesiva, aunque también existen casos de forma autosómica dominante y transformación espontánea, caracterizada por la presencia de niveles muy bajos de neutrófilos maduros en la sangre. Existen, aproximadamente 1-2 casos por millón y afecta principalmente a niños sin predilección por ningún sexO ${ }^{23}$.

Debido al gran descenso de neutrófilos circulantes, las defensas de estos pacientes están muy disminuidas por lo que están expuestos a diferentes infecciones como celulitis, estomatitis, meningitis, neumonía y sepsis. En encía se pueden encontrar cuadros agresivos caracterizados por inflamación gingival, edema, formación de bolsas periodontales y movilidad dentaria. El tratamiento odontológico en estos pacientes debería estar encaminado a prevenir las infecciones periapicales y periodontales.

\section{Alleraciones gingivales genéticas}

\section{Fibromatosis gingival here- ditaria (FGH)}

La FGH es una alteración que se transmite, generalmente, de forma autosómica dominante. Consiste en una hiperplasia de la encía insertada, del margen gingival y de las papilas interdentales que presenta un color rosado y una consistencia fibrótica. Tiene poca tendencia al sangrado y llega a cubrir una parte o la totalidad 


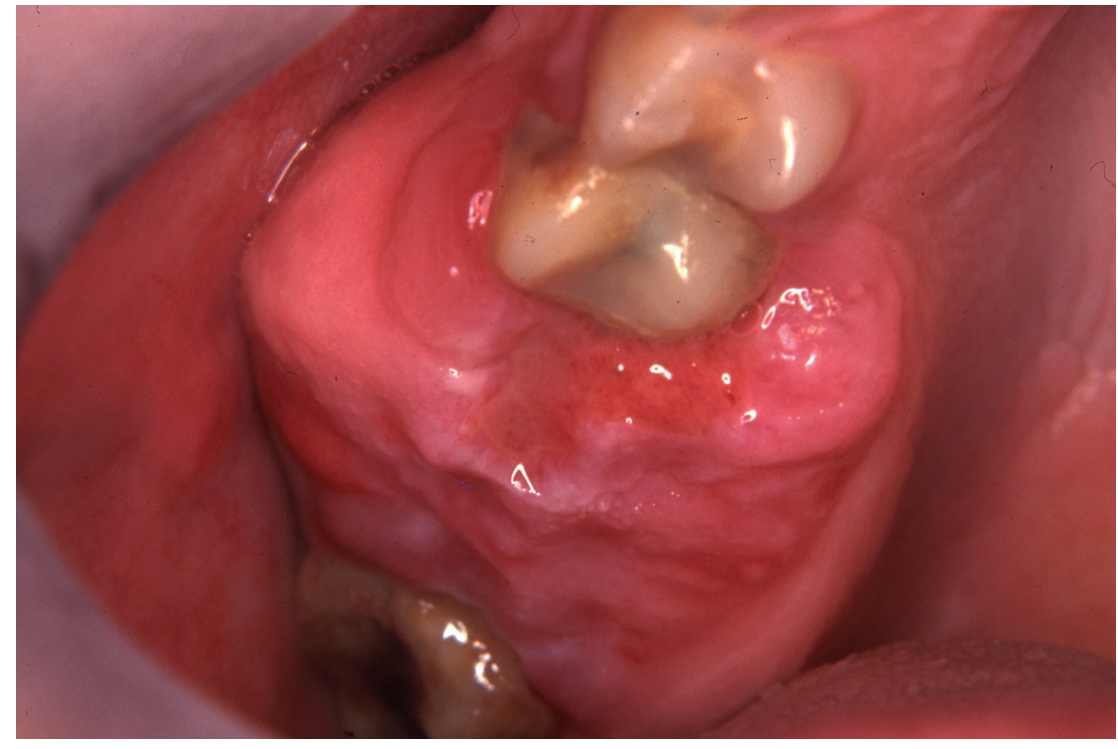

Figura 9. Fibromatosis gingival hereditaria localizada en la tuberosidad del maxilar.

de las coronas dentarias, pudiendo dar lugar a interferencias funcionales durante la fonación y la masticación, además de impedir el sellado labial. La hiperplasia no suele estar presente en el nacimiento y generalmente comienza con la erupción de la dentición permanente, aunque también puede desarrollarse durante la dentición temporal24. Ceneralmente el aumento gingival es simétrico, aunque puede ser unilateral y generalizado o localizado. La forma Iocalizada afecta a la zona de molares superiores y tuberosidad del maxilar, especialmente en la zona palatina ${ }^{25}$ (fig.9).

Puede aparecer como una entidad aislada o asociada a otras alteraciones sistémicas formando parte de algún síndrome hereditario como el querubismo, el síndrome de Laband, el síndrome de Klippel-Trenaunay-Weber o el síndrome de Ehlers-Danlos ${ }^{26}$.

El mecanismo celular por el que se produce no está del todo claro aunque se ha demostrado que los fibro- blastos sintetizan niveles más elevados de lo habitual de componentes de la matriz extracelular. Además la degradación de la matriz extracelular disminuye en estos pacientes ya que las metaloproteinasas están disminuidas, mientras que el factor de crecimiento $B 1$ aparece aumentado ${ }^{26}$. Todo esto provoca un desequilibrio en el mecanismo normal de síntesis y degradación de las moléculas dando, como resultado final, un aumento de fibras que provoca el aumento del volumen gingival.

\section{Conclusiones}

1. La mucosa oral es una localización a menudo única $\mathrm{y} / \mathrm{o}$ precoz de diversas alteraciones sistémicas.

2. Con mucha frecuencia, la presencia de placa bacteriana y de dientes con diversas restauraciones de diferentes materiales y calidad, hace que sea difícil diagnosticar algunos procesos ya que actúan modificando el aspecto clínico de las mismas.

3. Es importante que el profesional sea consciente de esta situación para poder identificar precozmente las diferentes patologías que puedan aparecer

\section{Bibliografía recomendada}

Para profundizar en la lectura de este tema, el/los autor/es considera/an interesantes los artículos que aparecen señalados del siguiente modo: *de interés **de especial interés.

1. Position paper. Oral features of mucocutaneous disorders. J Periodontol. 2003;74:1545-56.

2**. Bagán J, Muzio LL, Scully C. Mucous membrane pemphigoid. Oral Diseases. 2005;11:197-218. Revisión actualizada en la que se describen los aspectos epidemiológicos, etiopatogénicos, las características clínicas y el tratamiento del penfigoide de las mucosas.

3. Esparza Gómez GC, García Núñez JA, Seoane Lestón JM. Gingivitis descamativa: aproximación al diagnóstico. Periodoncia. 1997; 7:227-42.
4. Black M, Mignogna MD, Scully C. Pemphigus vulgaris. Oral Diseases. 2005;11:119-30.

5. Reyes Macías JF, Bagán Sebastián JV. Lupus eritematoso discoide. Revisión de la literatura y reporte de tres casos. Arch Odontoestomatol. 2002;18:53-61. 
6. Laine MA. Effect of pregnancy on periodontal and dental health. Acta Odontol Scand. 2002;60:257-64.

7. Garrido de Cabo N, Blanco Carrión J, Ramos Barbosa I. Enfermedad periodontal y embarazo. Periodoncia. 1999:9:31-40.

8**. Luang K, Wing L-Y C, Lin MT. Pathogenetic roles of angiogenic factors in pyogenic granuloma in pregnancy are modulated by female sex hormones. J Periodontol. 2002; 73:701-08.

Consiste en un estudio realizado en humanos, en ratones y en cultivos celulares, en el que se determina, mediante técnicas inmunológicas, la implicación de las hormonas sexuales femeninas en el desarrollo del granuloma piógeno.

9. DeRossi SS, Ciarrocca KN. Lichen planus, lichenoid drug reactions, and lichenoid mucositis. Dent Clin N Am. 2005;49:77-89.

10. Seymour RA, Thomason JM, Ellis JS. The pathogenesis of drug-induced gingival overgrowth. J Clin Periodontol. 1996;23:165-75.

11. Oettinger-Barak O, Machtei EE, Barak S, LNaaj IA. Cyclosporine-A induced gingival hyperplasia pemphigus vulgaris: literature review and report of a case. J Periodontol. 2000;71:650-56

12*.Doufexi A, Mina M, Ioannidou E. Gingival overgrowth in children: epidemiology, pathogenesis, and complications. A literature review. J Periodontol. 2005;76:3-10.

Artículo de revisión en el que se describen los principales tipos de hiperplasia gingival: la producida por fármacos, la fibromatosis gingival hereditaria y la neurofibromatosis.

13*. Das SJ, Newman HN, Olsen I. Keratinocyte growth factor receptor is up-regulated in cyclosporin A-induced gingival hyperplasia. J Dent Res. 2002;81:683-7.

En este estudio se analiza, in vivo y también in vitro, el papel del factor de crecimiento de los queratinocitos en el desarrollo de las hiperplasias gingivales relacionadas con el tratamiento con ciclosporina-A.

14. Cappuyns I, Gugerli P, Mombelli A. Viruses in periodontal disease-a review. Oral Diseases. 2005;11:219-29.

15. Campo-Trapero J, Cano-Sánchez J, RomeroGuerrero J, Moreno-López LA, Cerero-Lapiedra R, Bascones-Martínez A. Dental management of patients with human inmunodeficiency virus. Quintessence Int. 2003;34: 515-25.

16. Murria PA. HIV disease as a risk factor for periodontal disease. Compend Contin Educ Dent. 15:1053-63.

17*.Stoopler ET. Oral herpetic infections (HSV 18). Dent Clin N Am. 2005;49:15-29.

En este artículo se describen la características de la familia de los virus del herpes humano y las principales manifestaciones orales de las infecciones causadas por estos agentes.

18. Bagán Sebastián JV. Infecciones micóticas y herpéticas orales: características clínicas. Arch Odontoestomatol. 2004;20:169-74.
19. Pini Prato G, Rotundo R, Magnani C, Ficarra G. Viral etiology of gingival recession. A case report. J Periodontol. 2002;73:110-4.

20. Genc A, Atalay T, Gedikoglu G, Zulfikar B, Kullu S. Leukemic children: clinical and histopathological gingival lesions. J Clin Pediatr Dent. 1998; 22:253-6.

21. Chapple ILC, Saxby MS, Murray JA. Gingival hemorrage, myelodysplastic syndromes, and acute myeloid leukemia. A case report. J Periodontol. 1999;70:1247-53.

22. Pereira CM, Gasparetto PF, Coracin FL, Marqués JF, Lima CSP, Correa MEP. Severe gingival bleeding in a myelodysplastic patient: management and outcome. J Periodontol. 2004;75:483-6.

23. Hakki SS, Aprikyan AAG, Yildirim S, et al. Periodontal status in two siblings with severe congenital nutropenia: diagnosis and mutational análisis of the cases. J Periodontol. 2005;76:837-44

24. Baptista IP. Hereditary gingival fibromatosis: a case report. J Clin Periodontol. 2002;29:871-4.

25. Katz J, Guelmann M, Barak S. Hereditary gingival fibromatosis with distinct dental, skeletal and developmental abnormalities. Pediatr Dent. 2002;24:253-6.

26. Casavecchia P, Uzel MI, Kantarci A, Hasturk H, Dibart S, Hart TC, Trackman PC, Van Dyke TE. Hereditary gingival fibromatosis associated with generalized aggressive periodontitis: a case report. J Periodontol. 2004; 75:770-8. 